\title{
A Photocatalytic Active Adsorbent for Gas Cleaning in a Fixed Bed Reactor
}

\author{
Peter Pucher, ${ }^{1}$ Rabah Azouani, ${ }^{2}$ Andrei Kanaev, ${ }^{2}$ and Gernot Krammer ${ }^{3}$ \\ ${ }^{1}$ Department of Chemical Apparatus Design, Particle Technology and Combustion, Graz University of Technology, \\ Inffeldgasse 25/B, 8010 Graz, Austria \\ ${ }^{2}$ Laboratoire d'Ingénierie des Matériaux et des Hautes Pressions, CNRS, Institut Galilée, Université Paris-Nord, \\ 93430 Villetaneuse, France \\ ${ }^{3}$ Department of Energy and Process Engineering, Norwegian University of Science and Technology, Kolbjørn Hejes vei 1, \\ 7491 Trondheim, Norway
}

Correspondence should be addressed to Peter Pucher, peter.pucher@tugraz.at

Received 24 July 2007; Accepted 27 February 2008

Recommended by Russell Howe

\begin{abstract}
Efficient photocatalysis for gas cleaning purposes requires a large accessible, illuminated active surface in a simple and compact reactor. Conventional concepts use powdered catalysts, which are nontransparent. Hence a uniform distribution of light is difficult to be attained. Our approach is based on a coarse granular, UV-A light transparent, and highly porous adsorbent that can be used in a simple fixed bed reactor. A novel sol-gel process with rapid micro mixing is used to coat a porous silica substrate with $\mathrm{TiO}_{2}$-based nanoparticles. The resulting material posses a high adsorption capacity and a photocatalytic activity under UV-A illumination (PCAA = photocatalytic active adsorbent). Its photocatalytic performance was studied on the oxidation of trichloroethylene (TCE) in a fixed bed reactor setup in continuous and discontinuous operation modes. Continuous operation resulted in a higher conversion rate due to less slip while discontinuous operation is superior for a total oxidation to $\mathrm{CO}_{2}$ due to a user-defined longer residence time.
\end{abstract}

Copyright (c) 2008 Peter Pucher et al. This is an open access article distributed under the Creative Commons Attribution License, which permits unrestricted use, distribution, and reproduction in any medium, provided the original work is properly cited.

\section{INTRODUCTION}

Many pollutants, smells, and odors as well as bacteria and pathogens exist in the atmosphere. They influence the quality of life and they are sources of illnesses and allergies even if they are at very low concentrations. An abatement of these unwanted substances with state-of-the-art technology is either technically complex or energetically expensive. The photocatalytic oxidation technique represents a new and promising method for gas cleaning. Hence, the interest in photocatalytic chemistry is rising worldwide as demonstrated by high numbers of citations and patents [1]. However, upscaling and technical implementation of photocatalysis are difficult, which is one of the reasons why industrial realizations are still limited.

The basic problem of the photocatalytic processes scaleup for commercial utilization is to provide sufficient illuminated active surface area. A uniform distribution of light inside the reactor and provision of a high number of active surface sites per reactor volume unit are key parameters of a successful reactor design [2]. One approach to meet these requirements is based on a fixed bed reactor with an irradiated nanocoated fill. The used material should possess optimal optical properties and a large inner surface with unhindered access by pollutant to catalyst layer. Coarsegranular wide-pore silica is an excellent candidate because it has open porous structure and high-specific surface area, and it satisfies UV-light transmission [3].

In the present communication we report on a new photocatalytic active adsorbent (PCAA) as a combination of $\mathrm{TiO}_{2}$ sol nanoparticles immobilized on a UV-transparent coarsegranular porous silica support. The UV-light-triggered degradation of trichloroethylene is investigated and its kinetics is discussed.

\section{EXPERIMENTAL}

\subsection{Preparation and immobilization of nanoparticles}

The sol nanoparticles are prepared in a sol-gel reactor using titanium tetraisopropoxide (TTIP) as a precursor. This 


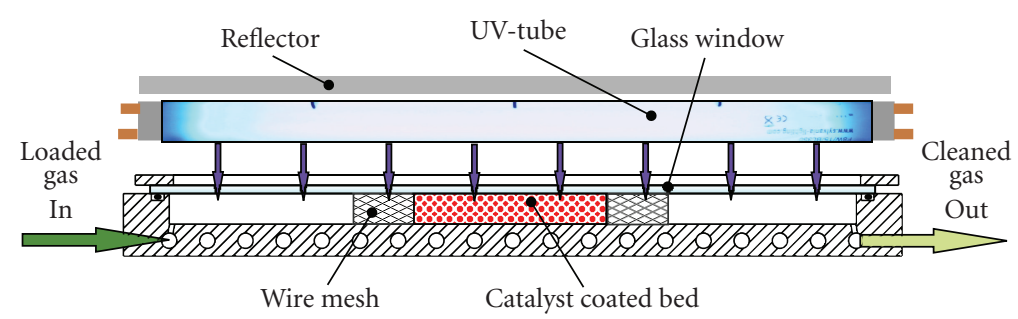

(a)

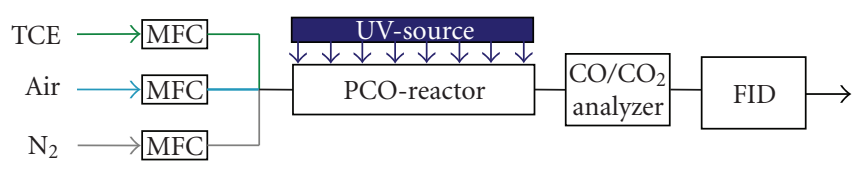

(b)

FIGURE 1: (a) Cut section of the photocatalytic reactor and (b) simplified flow sheet of the setup.

TABLE 1: BET surface and pore characteristics of PCAA.

\begin{tabular}{lcccc}
\hline Substrate & Mean grain size $(\mathrm{mm})$ & BET surface $\left(\mathrm{m}^{2} / \mathrm{g}\right)$ & Most abundant pore diameter $(\mathrm{nm})$ & Pore volume $(\mathrm{mm} / \mathrm{g})$ \\
\hline Porous silica granulate & $3-4$ & $330 \pm 30$ & $6 \pm 0.7$ & $810 \pm 70$ \\
\hline
\end{tabular}

reactor has been described in [4]. In present experiments, the standard operation conditions were conserved: two stock solutions of TTIP/propan-2-ol and $\mathrm{H}_{2} \mathrm{O}$ /propan-2-ol $\left(\mathrm{C}_{\mathrm{Ti}}=\right.$ $\left.0.146 \mathrm{M}, \mathrm{H}=\mathrm{C}_{\mathrm{H}_{2} \mathrm{O}} / \mathrm{C}_{\mathrm{Ti}}=2.46\right)$ were synchronously injected at high Reynolds numbers into the reactor container through the static Hartridge-Roughton-type T-mixer by applying a dry nitrogen gas pressure. The reactor temperature was maintained at $20.0^{\circ} \mathrm{C}$. As a result, metastable sol particles of size $2 \mathrm{R}=6.0 \mathrm{~nm}$ with a narrow size distribution were generated in the reactor. The sols slowly grow in size during the so-called induction period that amounts for $t_{\text {ind }}=55$ minutes. Particle immobilization was achieved during the period of their relative stability: $t<t_{\text {ind }} / 2$. The support was immersed into the reactive colloid for $\sim 25$ minutes, then withdrawn, cleaned, and dried. The $\mathrm{TiO}_{2}$ nanoparticles are involved into their bulk by capillary forces, then reacting on the internal surface of pores. Hence, they are immobilized on the support surface. After the drying stage in a glove box and then in an oven $\left(80^{\circ} \mathrm{C}\right)$, a calcination at $450^{\circ} \mathrm{C}$ was performed typically during 4 hours. The deposited catalyst mass on the porous substrate was measured as described in [5]. A mean value of $0.55 \mathrm{wt} . \%$ has been obtained.

\subsection{Photocatalytic reactor}

The photocatalytic performance of the prepared PCAA was studied in a fixed bed plug flow reactor setup, depicted in Figure 1. Trichloroethylene $\left(\mathrm{C}_{2} \mathrm{HCI}_{3}, \mathrm{TCE}\right)$ was used as a model pollutant at an inlet concentration varied from 25 to 300 ppmv. Purified-compressed air and $\mathrm{N}_{2}$ acted as carrier gas, free of oil, $\mathrm{CO} / \mathrm{CO}_{2}$, and humidity. The overall gas flow of $1 \mathrm{l} / \mathrm{min}$ s.t.p. was controlled by mass flow controllers. All experiments were carried out at ambient pressure and temperature $\left(\sim 1\right.$ bar, $\left.23 \pm 3^{\circ} \mathrm{C}\right)$ with dry gas. The inlet and outlet gas temperatures were monitored by two type-K thermocouples. The coated material was filled in the stainless steel reactor of a rectangular shape (fill size $50 \times 76 \times 11 \mathrm{~mm}^{3}$ ) covered by a UV-A transparent glass window. One UVA fluorescent tube (Sylvania BL350 8W, peak emission at $350 \pm 15 \mathrm{~nm}$ ) illuminated the material. Its performance was adjusted from $25 \%$ to $100 \%$ by an electronic ballast (Philips EVG HF-R 114 TL5). This corresponds to the integral intensity I varied from 0.68 to $5.35 \mathrm{~mW} / \mathrm{cm}^{2}$, measured with a Solatell Sola-Scope 2000 setup. The TCE concentration was measured by a flame-ionization detector (FID TESTA 123), which was calibrated with TCE gas before the measurements. A $\mathrm{CO} / \mathrm{CO}_{2}$ gas analyzer (NDIR Hartmann\&Braun URAS 14) measured the final products of the photocatalytic TCE oxidation. The reactor could be bypassed to measure the inlet concentrations.

\section{RESULTS AND DISCUSSION}

\subsection{Surface area and pore size}

The uncoated substrate and impregnated PCAA grains were analyzed for their total pore volume and pore size distribution with Hg-intrusion method (Porotec Inc., Niederhofheimer Str. 55a, 65719 Hofheim, Germany), and their internal surface area with BET method (STRÖHLEIN AREAmeter II). The nanoparticle coating process appears to have no significant influence on both pore volume and surface area. Table 1 summarizes the results for PCAA. The measured properties for coated and uncoated materials were found to be within the range of deviation due to inhomogeneities in the raw material. Thus, it can be concluded that 


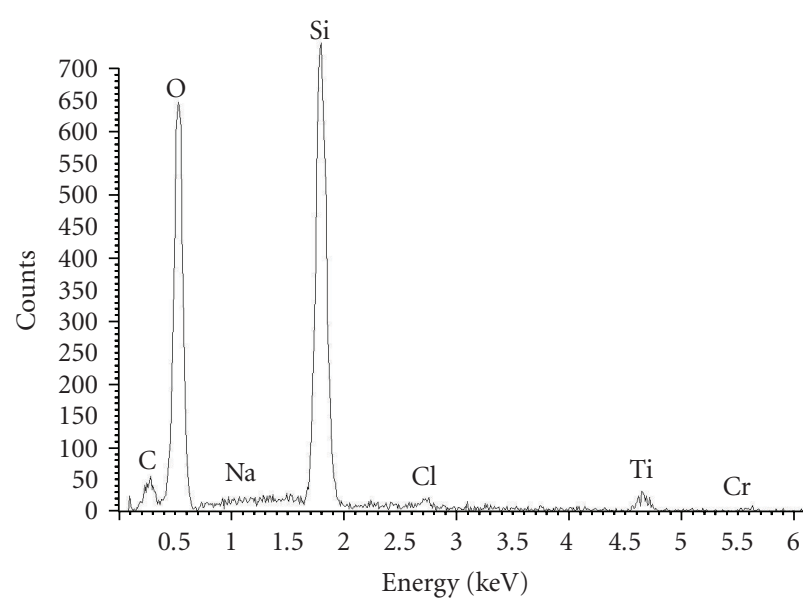

FIgURE 2: Electron microscope EDX spectrum of nano- $\mathrm{TiO}_{2}$ impregnated silica substrate PCAA (FELMI Graz).

hardly any pores are blocked by incorporated $\mathrm{TiO}_{2}$ particles. The pore size distribution of the substrate is broad enough to give sufficient room for nanoparticles already at wide pore diameters. On the other hand, an increase of the surface area due to the nanoparticles is low because of their low-mass load $(\sim 0.55$ wt.\%). Benmami et al. [5] have reported the specific surface of the noncrystalline $\mathrm{TiO}_{2}$ nanoparticles in the range of $480 \mathrm{~m}^{2} / \mathrm{g}$ correlated to their own mass. Being normalized on the total PCAA mass, this corresponds to an active surface area of about $2.7 \mathrm{~m}^{2} / \mathrm{g}$ or just $0.8 \%$ of the substrate surface.

\subsection{Morphology analysis of PCAA}

EDX (Zeiss DSM 982 GEMINI), XRD (XRG 3000 INEL), and TEM (JEOL $200 \mathrm{keV}$ ) measurements were carried out to characterize the immobilized catalyst nanoparticles on the inner substrate surface. Beneath the typical peaks for the silica substrate ( $\mathrm{Si}, \mathrm{O})$, the EDX spectrum (Figure 2 ) shows a small peak for titanium at about $4.5 \mathrm{keV}$. Because of a lowmass loading of $\mathrm{TiO}_{2}$ nanoparticles embedded in amorphous silica, the XRD patterns of PCAA showed no characteristic peaks. It was not possible to identify the crystalline phase of $\mathrm{TiO}_{2}$ with this method. High-resolution TEM measurements of PCAA bulk material have been performed to investigate particle size and distribution of the nanoparticular $\mathrm{TiO}_{2}$ mater. Figure 3 evidences rare nonagglomerated crystalline domains of size in the range between 5 and $10 \mathrm{~nm}$. These rare crystallites are surrounded by amorphous silica matrix visualized by low-contrast gray slabs and spots. A first approximation of their crystalline layer distances indicates the anatase phase.

\subsection{UV-absorption of the nanocoated substrates}

The UV transmission of a substrate is one important property, since a large active area has to be illuminated in practical applications. The substrate must not absorb photons at energies sufficient to elevate an electron from the valence band to the conduction band of the semiconductor.

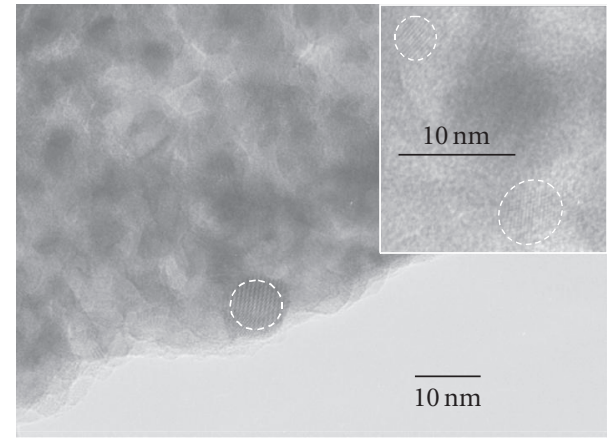

FIgURE 3: High-resolution TEM image of the $\mathrm{TiO}_{2}$ nanoparticles immobilized into the nanoporous silica substrate (LIMHP Paris).

A custom-made setup consisting of a big volume quartz cell $\left(55 \times 35 \mathrm{~mm}^{2}\right.$ window size $)$ with adjustable spacing and an 8W UV-A tube (Sylvania BL350) light source was used to measure the optical transparency dependence on the fill thickness $(10-30 \mathrm{~mm})$. The penetrating light was detected by a Chromex 250IS monochromator (grating 1501/mm, $f=30 \mathrm{~cm}$, slit $20 \mu \mathrm{m}$ ) equipped with a CCD detector (Princeton). Figure 4(a) shows the spectral dependence on the absorption shows a plateau with no particular band structure. Because the silica band gap is large, we assign this opacity to the light scattering on silica pores. On the other hand, the opacity of $\mathrm{TiO}_{2}$-coated PCAA exhibits a characteristic onset below $\sim 400 \mathrm{~nm}$, which corresponds to the bulk $\mathrm{TiO}_{2}$ anatase absorption [6]. Short-wave UV-light is thereby scattered and absorbed inside PCAA, while longwave UV/VIS light is transmitted through a fill of PCAA. This finding is documented by Figure 4(b)) which clearly shows a red shift of the normalized absorbance with increasing fill thickness.

\subsection{Photocatalytic oxidation in continuous mode}

First experiments were carried out under continuous gas feed and UV-A illumination. The photocatalytic performance of PCAA was studied by the TCE degradation rate $\left(r_{\mathrm{TCE}}\right)$ based on the volume of the fixed bed $\left(V_{\mathrm{FB}}\right)$. The experimental data of pollutant concentration (in ppmv) at inlet $\left(Y_{\mathrm{IN}}\right)$ and outlet ( $\left.Y_{\text {OUT }}\right)$ and the total molar gaseous flow $\dot{N}_{g}$ (in mol/s) were used to calculate the experimental rate $r_{\mathrm{TCE}, \exp }$ as presented in

$$
r_{\mathrm{TCE}, \exp }(\bar{Y})=\frac{\dot{N}_{g}}{V_{\mathrm{FB}}} \cdot\left(Y_{\mathrm{IN}}-Y_{\mathrm{OUT}}\right)\left(\frac{\mathrm{mol}}{\mathrm{m}^{3} \cdot \mathrm{s}}\right)
$$

Due to reactions, the TCE concentration decreases downstream of the gas flow. Thus assuming Langmuir-Hinshelwood reaction kinetics, this experimental rate is related to the logarithmic mean concentration $\bar{Y}$ between inlet and outlet:

$$
\bar{Y}=\frac{\left(Y_{\mathrm{IN}}-Y_{\mathrm{OUT}}\right)}{\ln \left(Y_{\mathrm{IN}} / Y_{\mathrm{OUT}}\right)}(\mathrm{ppmv})
$$




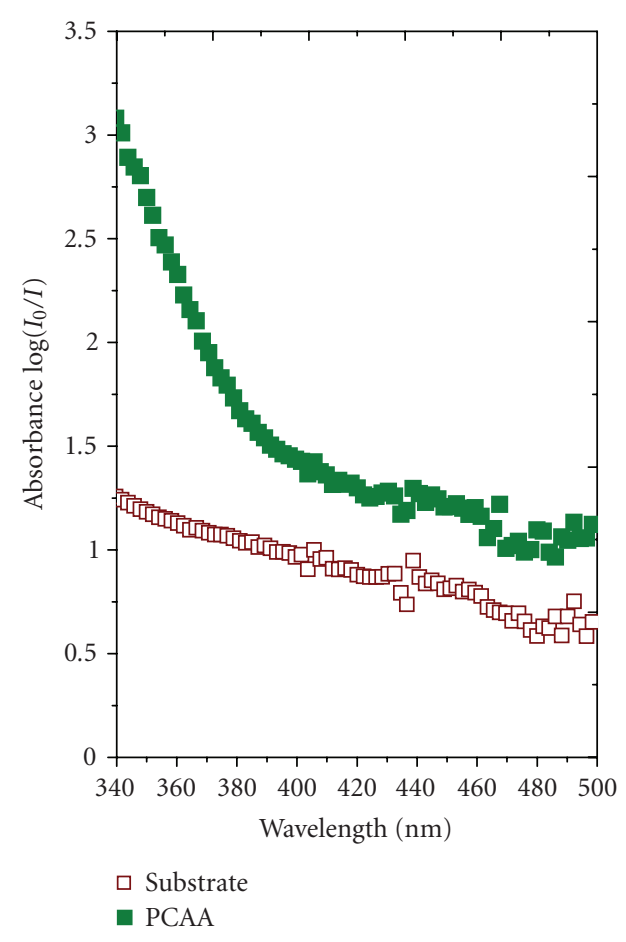

(a)

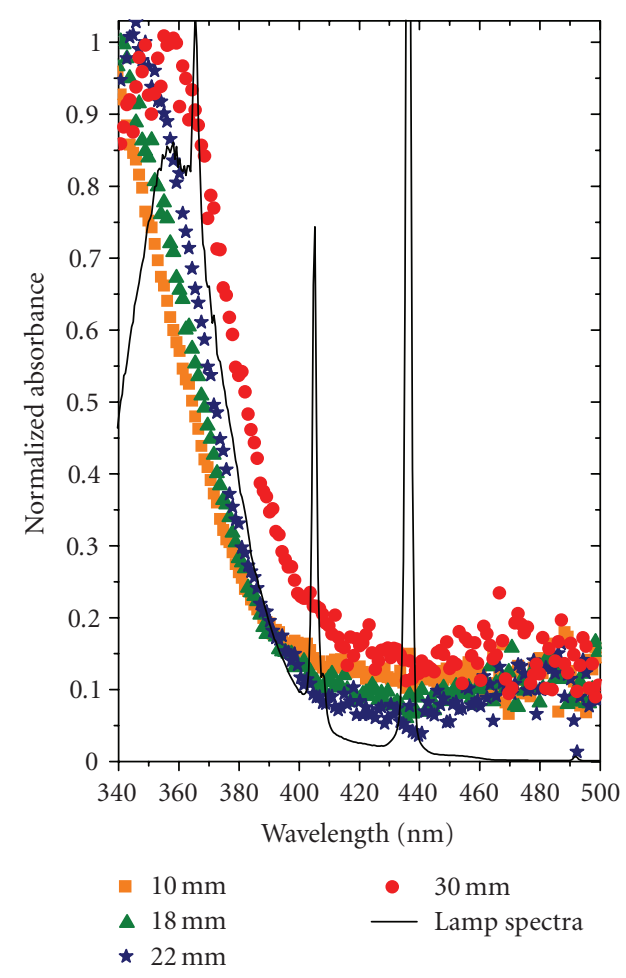

(b)

FIGURE 4: (a) Spectral dependence of the absorbance of pure and nano- $\mathrm{TiO}_{2}$ impregnated silica substrate. (b) Red-shift of the normalized absorbance with increasing fill thickness of PCAA.

Among different kinetic studies concerning the photocatalytic oxidation of TCE reported in literature (see, e.g., Anderson et al. [7], Demeestere et al. [8], Doucet et al. [9]), we found that none of them provided sufficient information about the reaction rate dependence on light intensity over a wide range of concentrations. Our experimental kinetic study was performed in continuous operation mode for different inlet concentrations and varying light intensity $I$. We developed a modified Langmuir-Hinshelwood kinetic model to accommodate the influence of the concentration and light intensity on the TCE decomposition rate $r_{\mathrm{TCE}}$ :

$$
r_{\mathrm{TCE}}(Y, I)=\frac{k_{I} \cdot K_{\mathrm{Ad}} \cdot Y}{1+K_{\mathrm{Ad}} \cdot Y} \cdot\left(1-e^{-C \cdot\left(I / I_{\max }\right)}\right)\left(\frac{\mathrm{mol}}{\mathrm{m}^{3} \cdot \mathrm{s}}\right) .
$$

The influence of the light intensity $I$ is expressed by the exponential term of (3). Thereby, the intrinsic light intensity $I$ was related to the maximal intensity $I_{\max }\left(5.36 \mathrm{~mW} / \mathrm{cm}^{2}\right)$. A dimensionless adjustable parameter $C$, with no further physical meaning, was used as a fit parameter. This exponential term was suggested to describe best the observed saturation behavior over the applied concentration range. Figure 5 illustrates this behavior in a 3D surface fit. The points set for the experimental data obtained with (1) and (2), while the surface presents the calculated model according to (3), computed with the kinetic parameters of Table 2 . The model satisfactorily describes the measured data with a highcorrelation coefficient $r^{2}$ of 0.976 .

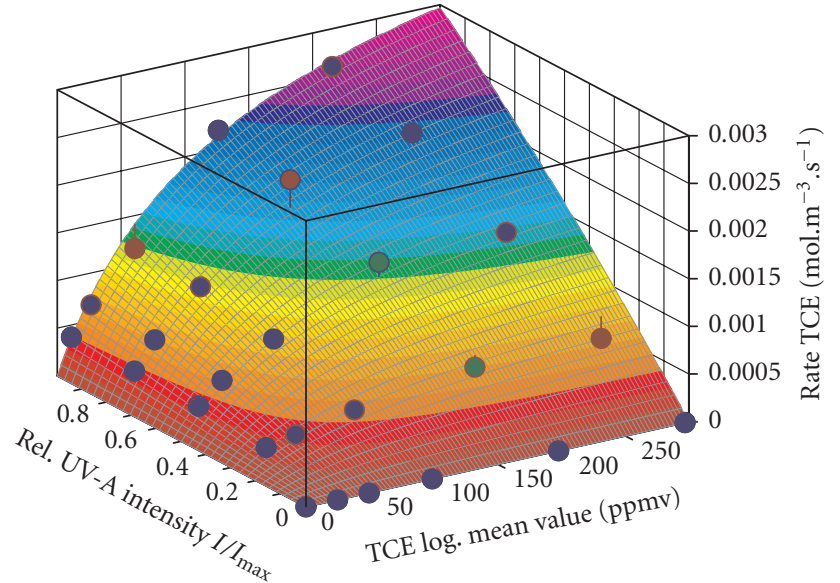

Figure 5: Experimental results (dots) and kinetic fit for the photocatalytic oxidation of TCE on PCAA in dependence of concentration and light intensity.

\subsection{Photocatalytic oxidation in discontinuous mode}

PCAA possesses a large inner surface and hence a high capacity for the adsorption of polar pollutant molecules. In case of TCE, experiments resulted in the adsorption of about $1.4 \mathrm{mg} / \mathrm{g}$ at $100 \mathrm{ppmv}\left(23^{\circ} \mathrm{C}\right)$ and no UV-A illumination. This adsorption capacity combined with the photocatalytic 
TABLE 2: Calculated kinetic parameters for the photocatalytic oxidation of TCE (25-300 ppm) on PCAA in dependence of UV-A light intensity $\left(0-5.35 \mathrm{~mW} / \mathrm{cm}^{2}, 11 \mathrm{~mm}\right.$ fill thickness).

\begin{tabular}{lcccc}
\hline Catalyst & Rate $k_{\mathrm{I}}\left(\mathrm{mol} \cdot \mathrm{m}^{-3} \cdot \mathrm{s}^{-1}\right)$ & Adsorption constant $\mathrm{K}_{\mathrm{Ad}}\left(\mathrm{ppm}^{-1}\right)$ & Light constant $C(1)$ & Correlation $r^{2}(1)$ \\
\hline PCAA & 0.0149 & 0.0085 & 0.325 & 0.9769 \\
\hline
\end{tabular}

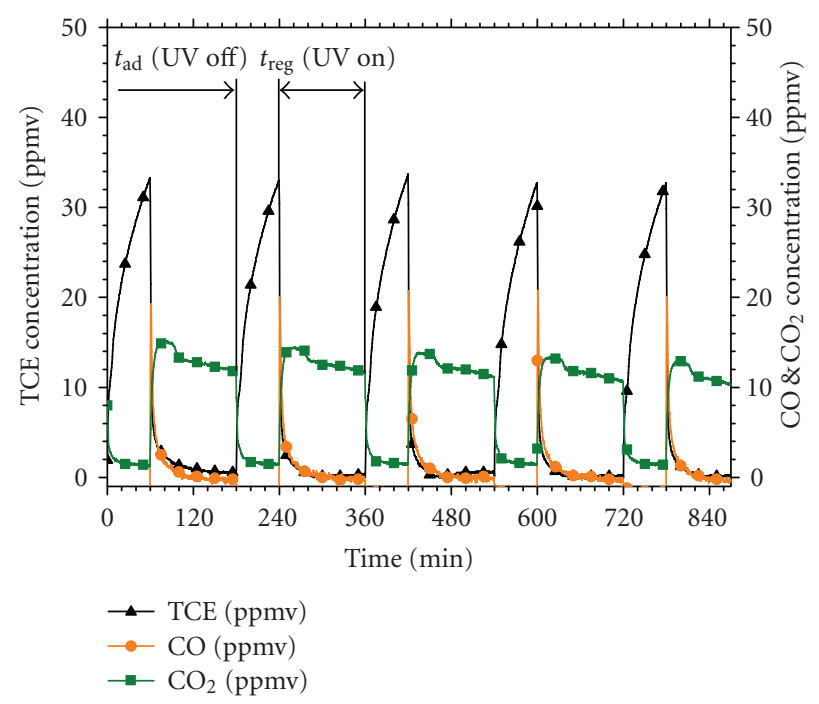

Figure 6: Transient TCE, $\mathrm{CO}$, and $\mathrm{CO}_{2}$ concentration at reactor outlet for the discontinuous oxidation of TCE on PCAA $(50 \mathrm{ppm}$ TCE inlet concentration, mode $\mathrm{B}: t_{\mathrm{reg}}=2 \cdot t_{\mathrm{ad}}=120$ minutes).

activity can be used to run a reactor unit equipped with PCAA in a discontinuous mode for gas cleaning purposes. In this regime, first the adsorption step occurs of a pollutant from the raw gas stream under no UV-A illumination, followed by a regeneration step with/without clean air flush under UV-A illumination. Zou et al. [10] described the photocatalytic oxidation of toluene on titania-silica pellets in alternating adsorption/regeneration mode. A higher removal efficiency is generally expected with an increased regeneration time.

To test PCAA in discontinuous operation conditions, we conducted experiments at 50 ppmv and 100 ppmv TCE inlet concentration under two different conditions. Mode A was designed with the adsorption time $t_{\mathrm{ad}}=60$ minutes and equal regeneration time $t_{\text {reg }}=t_{\mathrm{ad}}$. Mode $\mathrm{B}$ was designed with a twice longer regeneration time $t_{\text {reg }}=2 \cdot t_{\mathrm{ad}}(120$ minutes). During regeneration, the reactor was flushed with $11 /$ min s.t.p. clean air and UV-A light was on with the maximum lamp performance $\left(5.36 \mathrm{~mW} / \mathrm{cm}^{2}\right)$. Figure 6 shows the transient analyzer signals for Mode B at $50 \mathrm{ppmv}$ TCE inlet concentration. Since the fill volume was small $\left(42 \mathrm{~cm}^{3}\right)$, a certain amount of TCE passed as slip the fixed bed reactor during the adsorption step (UV-A lamps off). Around $50 \%$ of the incoming TCE molecules were emitted on this stage. During the regeneration step only a very low TCE quantities were emitted and the adsorbed TCE was stored in PCAA, being slowly oxidized by the photocatalytic process until the next adsorption step.

\section{6. $\mathrm{CO}$ and $\mathrm{CO}_{2}$ products formation during continuous and discontinuous operation modes}

A complimentary possibility in evaluation of the material photocatalytic performance is to follow the reaction products formation. $\mathrm{CO}_{2}$ is the most desired final product of this process. Table 3 compares the main figures of overall conversion efficiency, oxidation rate $\mathrm{C}_{\mathrm{OX}} / \mathrm{C}_{\mathrm{TCE}}$, and ratio of produced $\mathrm{CO}_{2}$ versus $\mathrm{CO}$ in discontinuous and continuous operation modes. This comparison shows a much higher conversion efficiency in the continuous mode compared to the discontinuous one. This is well supported by the high slip of our setup during the adsorption step, as we defined conversion efficiency as $\left(\mathrm{TCE}_{\mathrm{IN}}-\mathrm{TCE}_{\mathrm{OUT}}\right) / \mathrm{TCE}_{\mathrm{IN}}$. The main advantage of the discontinuous operation mode is the longer residence time of the pollutant in PCAA. Hence, a much higher conversion of TCE to $\mathrm{CO}$ and $\mathrm{CO}_{2}$ can be achieved. This is illustrated by the $\mathrm{C}_{\mathrm{OX}} / \mathrm{C}_{\mathrm{TCE}}$ ratio, which is computed out of a carbon balance for adsorbed/reacted TCE to produced $\mathrm{CO}$ and $\mathrm{CO}_{2}$. Furthermore, a full oxidation to $\mathrm{CO}_{2}$ is preferred with longer regeneration time, which is illustrated by a higher $\mathrm{CO}_{2} / \mathrm{CO}$ ratio for mode $\mathrm{B}$. For all discontinuous tests, the computed oxidation rate was smaller than 1 which implies that a larger-quantity pollutant was adsorbed than oxidized at the regeneration steps. Hence, the regeneration time was too short and the system was still in an unsteady regime after $\sim 15$ hours operation in mode B. Out of this finding, it can be concluded that TCE is to be converted into chlorinated intermediates (e.g., DCAC $[11,12]$, Phosgene $[11-13]$, etc.) in a first fast reaction step. FTIR measurements proved the presence of DCAC and phosgene in the off-gas stream of the photo-reactor. Since their high polarity, these chlorinated intermediates can remain adsorbed onto the polar PCAA surface and oxidized slowly to the final oxidation products including $\mathrm{CO}$ and $\mathrm{CO}_{2}$. We assume a first-order kinetic reaction with the molar load of hydrocarbon in PCAA as determining concentration. Figure 7 shows the transient outlet concentration of $\mathrm{CO} / \mathrm{CO}_{2}$ during a long-term regeneration step. Thereby, the plotted lines were calculated with a first-order reaction scheme. A detailed analysis of the reaction pathways was not subject of the present communication.

\section{CONCLUSION}

A photocatalytic active adsorbent (PCAA) was prepared by coating a coarse granular porous silica with $\mathrm{TiO}_{2}$ nanoparticles in a sol-gel reactor. The used substrate acts as adsorbent possessing a high inner surface $\left(\mathrm{BET}=330 \mathrm{~m}^{2} / \mathrm{g}\right)$ with an open wide pore structure. A high-resolution TEM image revealed a particle size of $5-10 \mathrm{~nm}$. The crystalline 
TABLE 3: Conversion efficiency, slip during adsorption, oxidation ratio, and $\mathrm{CO}_{2}$-to-CO ratio for regeneration time equals adsorption time $\left(t_{\mathrm{reg}}=t_{\mathrm{ad}}\right.$, mode A), regeneration time twice adsorption time $\left(t_{\mathrm{reg}}=2 \cdot t_{\mathrm{ad}}\right.$, mode $\left.\mathrm{B}\right)$, and continuous operation $($ mode $\mathrm{C})$.

\begin{tabular}{|c|c|c|c|c|c|}
\hline TCE inlet ppm & Mode & Total TCE conversion (\%) & Slip during adsorption (\%) & $\mathrm{C}_{\mathrm{OX}} / \mathrm{C}_{\mathrm{TCE}}(\%)$ & $\mathrm{CO}_{2} / \mathrm{CO}(1)$ \\
\hline \multirow{3}{*}{50} & A & 45 & 51 & 32 & 2.73 \\
\hline & $\mathrm{B}$ & 44 & 49 & 65 & 3.43 \\
\hline & $\mathrm{C}$ & 89 & - & 25 & 1.75 \\
\hline \multirow{3}{*}{100} & $\mathrm{~A}$ & 38 & 55 & 30 & 2.04 \\
\hline & $\mathrm{B}$ & 40 & 53 & 48 & 3.05 \\
\hline & $\mathrm{C}$ & 73 & - & 28 & 1.61 \\
\hline
\end{tabular}

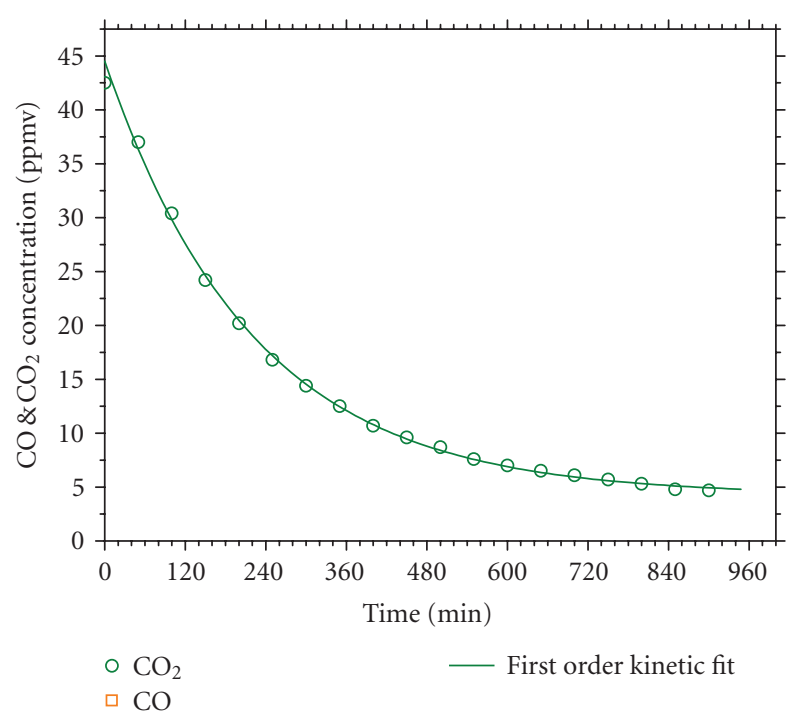

FIgURE 7: Transient CO, $\mathrm{CO}_{2}$ concentration at reactor outlet for a long-term regeneration run. The measured data points were fitted with a first-order kinetic fit (line).

particles are isolated embedded in the amorphous silica matrix. Experimental test for the photocatalytic oxidation of trichloroethylene (TCE) was conducted in a fixed-bed reactor setup under dry conditions. A study of influence of the pollutant concentration and UV-A light intensity was performed in a continuous operation mode. An adapted Langmuir-Hinshelwood kinetic model was found to satisfactorily describe the measured TCE destruction rate. The continuous operation mode resulted in a higher TCE conversion efficiency but a lower oxidation ratio to $\mathrm{CO}$ and $\mathrm{CO}_{2}$ than the discontinuous operation mode. The main problem of a discontinuous operation was the slip of pollutant during the adsorption step. This problem can be solved by a longer length of the PCAA fill. The $\mathrm{CO}$ and $\mathrm{CO}_{2}$ production rates were found to be directly dependent on the amount of pollutant or intermediate adsorbed in PCAA rather than on the inlet concentration.

PCAA can be regenerated by the photocatalytic oxidation process. This opens up new and alternative ways in photocatalytic reactor design and gas cleaning technology. Our results indicate a large material potential for applications at low pollutant concentrations and small to medium gas flow rates.
Recent experiments indicate a photo-induced activity of the uncoated substrate for the destruction of TCE developed after some UV-A illumination time. This currently unknown process maybe driven by a chlorine radical reaction. Further experiments with photocatalytic oxidation of methanol on PCAA are under way.

\section{ACKNOWLEDGMENTS}

This work is supported by the COST D41 Actions of the European Commission and Franco-Norwegian cooperation program AURORA. One of the authors gratefully acknowledges the experimental support by the Research Institute for Electron Microscopy at Graz University of Technology.

\section{REFERENCES}

[1] D. M. Blake, "Bibliography of work on the heterogeneous photocatalytic removal of hazardous compounds from water and air," Tech. Rep. NREL/TP-510-31319, NREL, Golden, Colo, USA, 2001.

[2] D. Bahnemann, "Photocatalytic water treatment: solar energy applications," Solar Energy, vol. 77, no. 5, pp. 445-459, 2004.

[3] P. Pucher, M. Benmami, G. Krammer, K. Chhor, J.-F. Bocquet, and A. Kanaev, "Photocatalytic activity of sol-gel derived $\mathrm{TiO}_{2}$ nanocoatings toward trichloroethylene decomposition in the gas phase," in Proceedings of the International Congress on Particle Technology (PARTEC '07), Nuremberg, Germany, March 2007.

[4] M. Rivallin, M. Benmami, A. Kanaev, and A. Gaunand, "Solgel reactor with rapid micromixing: modelling and measurements of titanium oxide nano-particle growth," Chemical Engineering Research and Design, vol. 83, no. A1, pp. 67-74, 2005.

[5] M. Benmami, K. Chhor, and A. V. Kanaev, "Supported nanometric titanium oxide sols as a new efficient photocatalyst," Journal of Physical Chemistry B, vol. 109, no. 42, pp. 1976619771, 2005.

[6] M. R. Hoffmann, S. T. Martin, W. Choi, and D. W. Bahnemann, "Environmental applications of semiconductor photocatalysis," Chemical Reviews, vol. 95, no. 1, pp. 69-96, 1995.

[7] M. A. Anderson, S. Yamazaki-Nishida, and S. Cervera-March, "Photodegradation of trichloroethylene in the gas phase using $\mathrm{TiO}_{2}$ porous ceramic membrane," in Photocatalytic Purification and Treatment of Water and Air, D. F. Ollis and H. Al-Ekabi, Eds., pp. 405-420, Elsevier, Amsterdam, The Netherlands, 1993. 
[8] K. Demeestere, A. De Visscher, J. Dewulf, M. Van Leeuwen, and H. Van Langenhove, "A new kinetic model for titanium dioxide mediated heterogeneous photocatalytic degradation of trichloroethylene in gas-phase," Applied Catalysis B, vol. 54, no. 4, pp. 261-274, 2004.

[9] N. Doucet, F. Bocquillon, O. Zahraa, and M. Bouchy, "Kinetics of photocatalytic VOCs abatement in a standardized reactor," Chemosphere, vol. 65, no. 7, pp. 1188-1196, 2006.

[10] L. Zou, Y. Luo, M. Hooper, and E. Hu, "Removal of VOCs by photocatalysis process using adsorption enhanced $\mathrm{TiO}_{2}-\mathrm{SiO}_{2}$ catalyst," Chemical Engineering and Processing, vol. 45, no. 11, pp. 959-964, 2006.

[11] S.-J. Hwang, C. Petucci, and D. Raftery, "In situ solid-state NMR studies of trichloroethylene photocatalysis: formation and characterization of surface-bound intermediates," Journal of the American Chemical Society, vol. 120, no. 18, pp. 43884397, 1998.

[12] P. B. Amama, K. Itoh, and M. Murabayashi, "Photocatalytic oxidation of trichloroethylene in humidified atmosphere," Journal of Molecular Catalysis A, vol. 176, no. 1-2, pp. 165-172, 2001.

[13] K.-H. Wang, H.-H. Tsai, and Y.-H. Hsieh, "The kinetics of photocatalytic degradation of trichloroethylene in gas phase over $\mathrm{TiO}_{2}$ supported on glass bead," Applied Catalysis $B$, vol. 17, no. 4, pp. 313-320, 1998. 


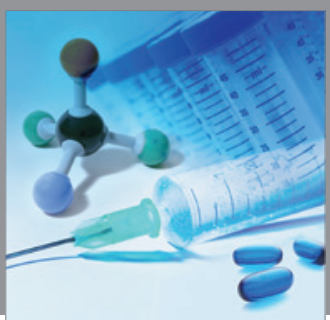

International Journal of

Medicinal Chemistry

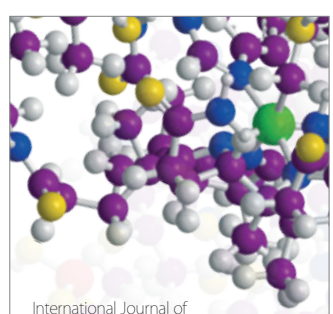

Carbohydrate Chemistry

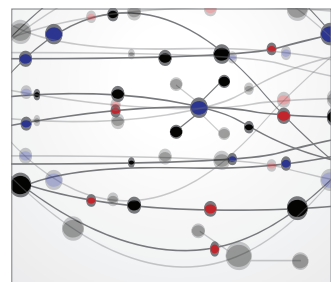

The Scientific World Journal
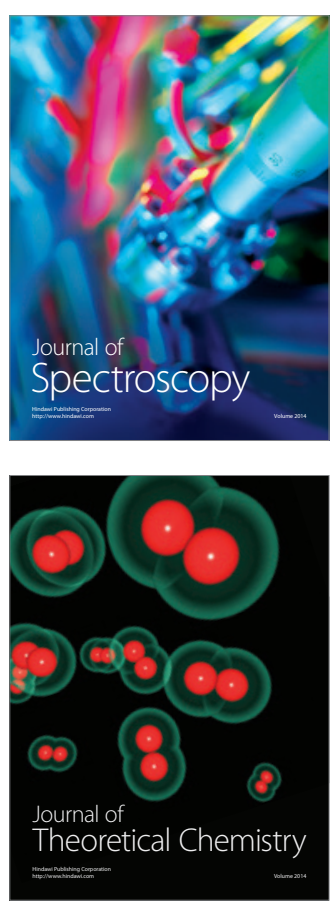
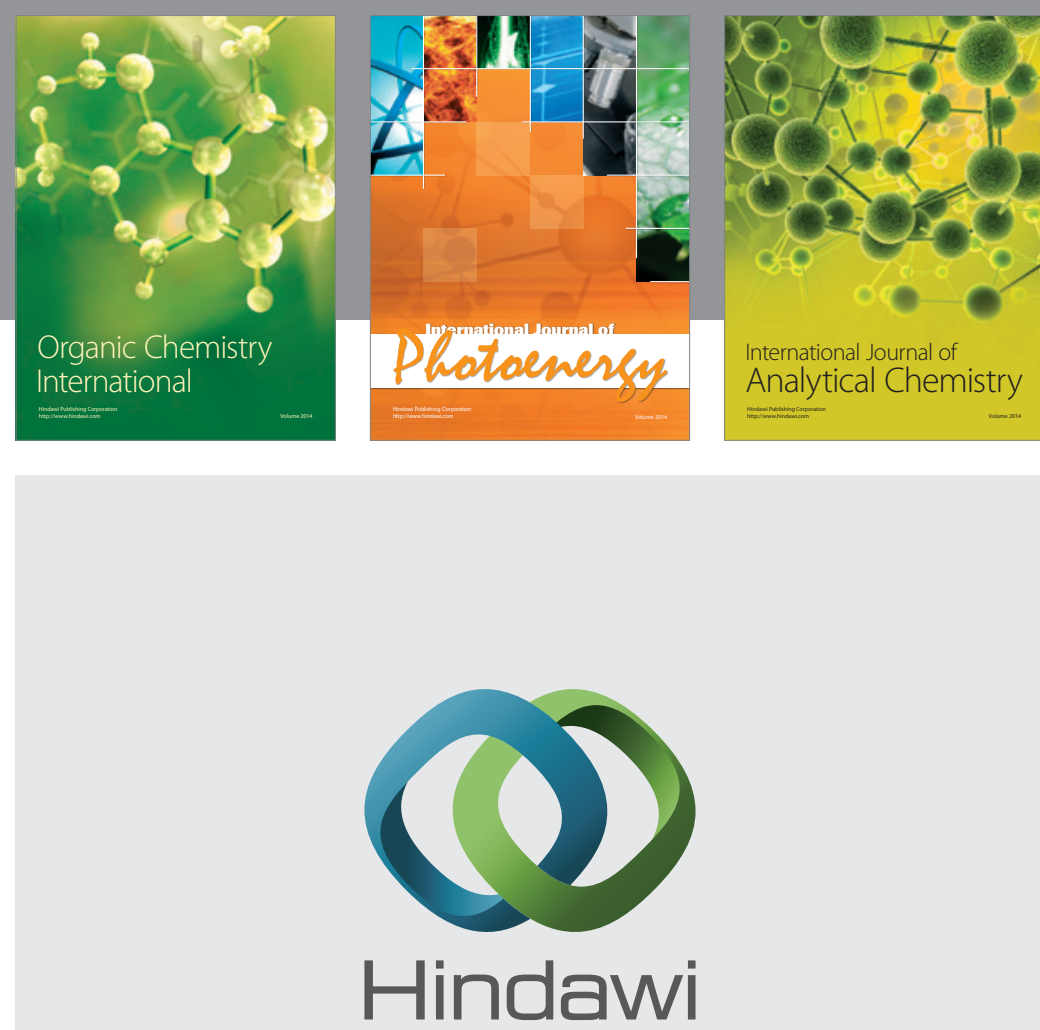

Submit your manuscripts at

http://www.hindawi.com
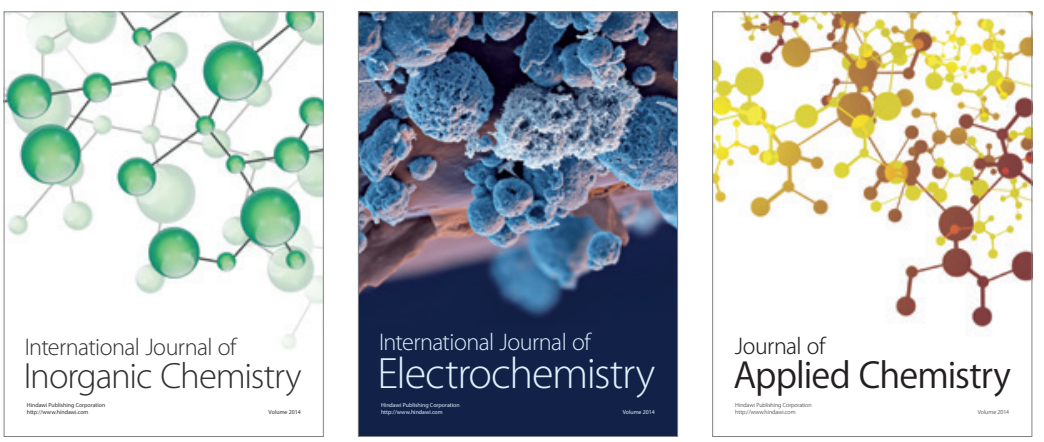

Journal of

Applied Chemistry
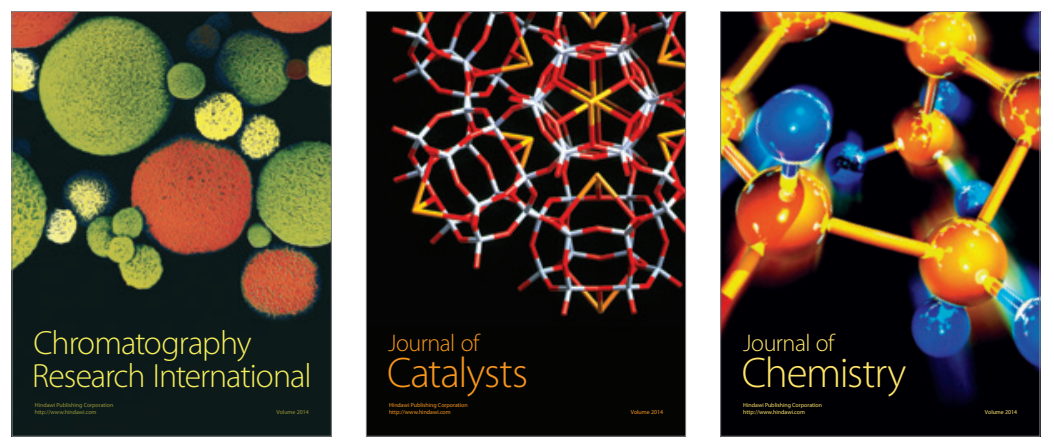
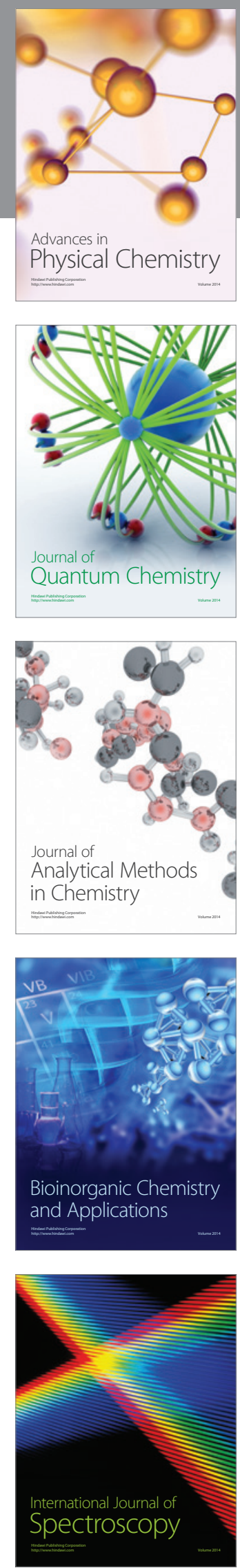